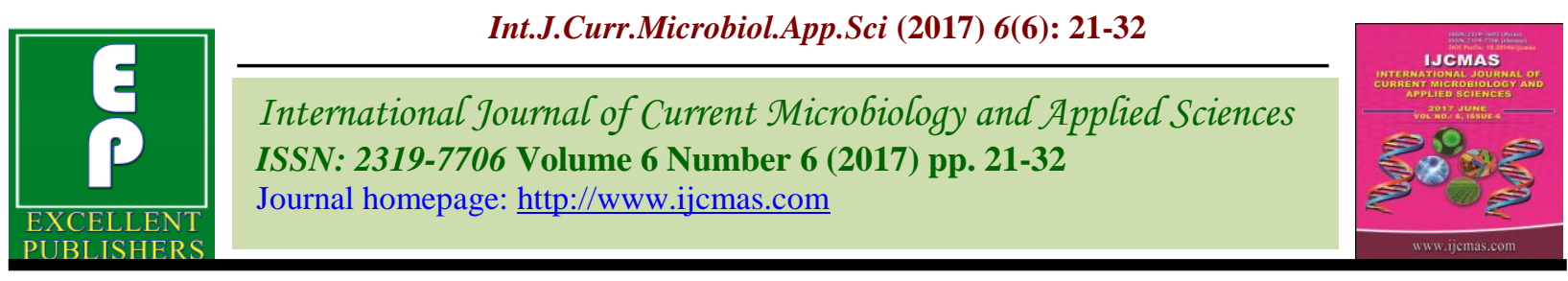

Review Article

https://doi.org/10.20546/ijcmas.2017.606.002

\title{
Advanced Breeding Strategies to Mitigate the Threat of Yellow Stripe Rust of Wheat
}

\author{
F.A. Sheikh ${ }^{1 *}$, Z.A. Dar, P.A. Sofi, Ajaz A. Lone and Nazir Ahmad Shiekh ${ }^{2}$ \\ ${ }^{1}$ Division of Genetics and Plant Breeding, Sher-e-Kashmir University of Agricultural Sciences \\ and Technology, Kashmir, India \\ ${ }^{2}$ Department of Botany, Barkatullah University of Bhopal, M.P., India \\ *Corresponding author
}

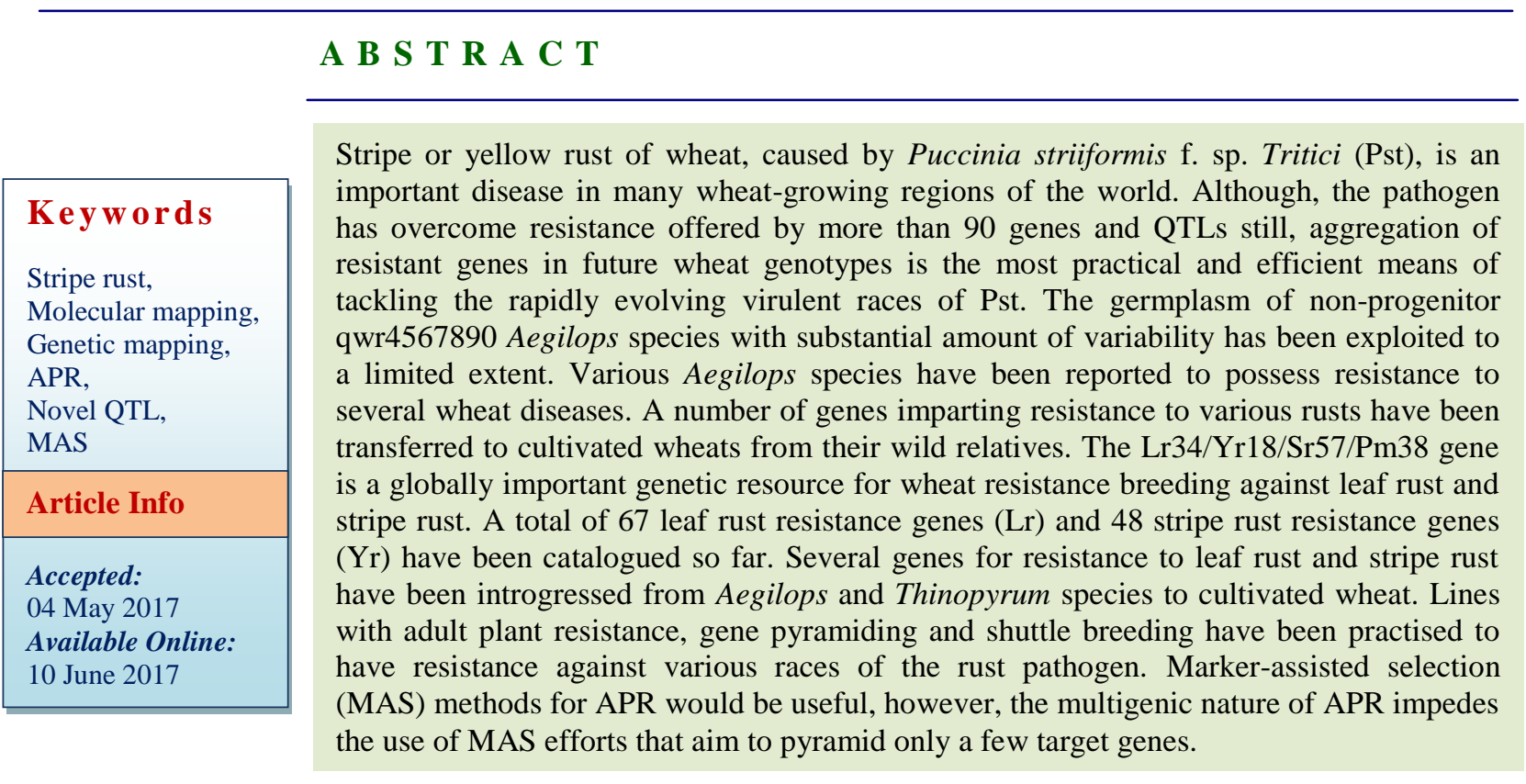

\section{Introduction}

Stripe or yellow rust (YR), caused by Puccinia striiformis f. sp. tritici, has reportedly caused significant yield losses in more than 60 countries (Stubbs 1985; Chen 2005). Recently, YR has become a serious threat to wheat, causing 50-100\% yield losses due to the breakdown of existing resistance genes and gradual adaptation of new strains in warmer regions, particularly the Central and West Asia and North Africa (CWANA) region (ICARDA, 2011). The breakdown of the widely used race-specific genes (R-genes) Yrl7 (Bayles et al., 2000; Wan et al., 2004; Chen 2007), Yr27 (Singh et al., 2004; Wan et al., 2004), Yr31 (Singh et al., 2011; Rosewarne et al., 2012), and Lr24 (Park et al., 2002) has created a serious challenge for wheat scientists and growers worldwide. Introducing genetic resistance into cultivars is the most economic and environmentally safe measure of rust disease management in wheat. To date, more than 71 
LR and 53 YR resistance genes have been identified and catalogued in different Triticum and related species or genera (McIntosh et al., 2012; Singh et al., 2013; Xu et al., 2013). Most of the formally designated genes confer race-specific resistance, which often loses effectiveness within a few years of deployment because cultivars with single Rgenes facilitate selection for virulent races (Bolton et al., 2008). Though most R-genes display high levels of resistance against the pathogen, and selection is therefore a relatively easy task, the longevity of those genes is only 3-5 years in a new cultivar (Singh, 2012). In the current scenario, the genes $\mathrm{Yr} 5$ and $\mathrm{Yr} 10$ may play a crucial role in the yellow rust breeding programme as they have shown field resistance and are effective against the prevalent races of yellow rust pathogen. Hence, detection of these genes can be very useful in wheat improvement programmes (Talha et al., 2016)

Currently, the most effective methods for disease management are cultural control, fungicide applications and resistance, the latter being the most environmentally friendly and cost-effective approach (Roelfs et al., 1992). Cytogenetic and mapping studies to identify resistance in wheat have led to the naming of more than $70 \mathrm{Yr}$ genes, but there are many more with temporary designations (Mcintosh et al., 1995). The identification and incorporation of $\mathrm{Yr}$ genes has significantly benefited wheat growing regions affected by stripe rust. Efforts to develop markers for $\mathrm{Yr}$ genes have helped facilitate marker-assisted selection (MAS) and introgression of APR and ASR into elite breeding lines (Distelfeld et al., 2006; Murphy et al., 2009).

Molecular markers allow breeders to identify and select the presence or absence of genes in early generation populations, and only carry forward material indicative of resistance. These lines are then followed up with disease phenotyping to confirm resistance. They are especially valuable in identifying quantitative traits or screening seedlings for APR resistance (Chen et al., 2013). Molecular markers are also valuable when combining APR into a line with ASR, which because of its high level of resistance and continuous expression masks the effect of APR. In addition, MAS can facilitate more lines screened in earlier generations, pyramiding of resistance genes, and potentially reduces the time to release a new variety (Collard et al., 2008). By improving the efficiency of disease resistance breeding, MAS may be a key part of increasing wheat production in the future as new Puccinia striiformis f. sp. tritici (Pst) races evolve.

Many prominent APR genes, such as Lr34/Yr18/ Sr57/Pm38 (Dyck1987; McIntosh 1992; Singh 1992; Spielmeyer et al., 2005; Lillemo et al., 2008; Krattinger et al., 2009), Lr46/Yr29/Sr58/Pm39 (Singh et al.,1998; William et al., 2003; Lillemo et al., 2008), Lr67/Yr46/ Sr55/Pm46 (Herrer Foessel et al., 2011; Hiebert et al., 2011), Yr36 (Fu et al., 2009), Sr2/Yr30 (Singh et al., 2000; Suenaga et al., 2003), and Lr68 (Herrera-Foessel et al., 2012), have been well characterized. Similarly, during the last 15 years, several molecular mapping studies have reported dozens of quantitative trait loci (QTL) distributed throughout all 21 chromosomes for YR resistance, and at least in 20 chromosomes for LR resistance in hexaploid wheat germplasm (Naz et al., 2008; Basnet 2012; Singh 2012). Nonetheless, the identification of new sources of durable resistance and their molecular characterization is a continual process in ensuring genetic diversity in breeding programs that aim to develop advanced lines or cultivars with high and stable yield potential, besides having durable rust resistance and other desirable characteristics. 
Quaiu 3, a high-yielding spring wheat line developed by the International Maize and Wheat Improvement Center (CIMMYT), displays a high level of resistance against LR and YR under field conditions. Recently, two sister lines of Quaiu 3 were released as the cultivars Koshan 09 (Afghanistan) and Gambo (Ethiopia) (CIMMYT Wheat Atlas: http://wheatatlas.cimmyt.org/country/varieties/

AFG/0). Quaiu 3 does not seem to carry any effective seedling resistance genes for YR resistance, as it displays high infection type (IT) ratings in seedling screenings (IT 6-8 on the $0-9$ scale, depending on Mexican $P$. striiformis races and the greenhouse environment). However, it carries a moderately effective race-specific LR resistance gene ( $L r 42)$, initially transferred from Aegilops tauschii to the winter wheat line KS91WGRC11 (Basnet et al., 2013). In a previous study, Basnet et al., (2013) also estimated a minimum of three genes conferring resistance to both LR and YR in Quaiu 3. In addition to Lr42, they also suggested that Quiau 3 carries two APR genes, Yr29 and Yr30, based on closely linked molecular markers. However, these known genes alone were not able to display near immune resistance to both LR and YR as in resistant parent Quaiu 3 (Basnet et al., 2014).

\section{Sr2/Yr30 Gene}

The gene, $S r 2$ was transferred to hexaploid wheat from tetraploid emmer wheat cultivar Yaroslav in 1920. It is present on chromosome 3BS and is also reported to be associated with $\operatorname{Lr} 27$ (Singh and McIntosh 1984). It is completely linked with pseudo black chaff $(\mathrm{Pbc})$, which is used as morphological marker for identification of lines carrying this gene. The genotypes with $\mathrm{Pbc}$ show varying level of stem rust infection. The maximum severity level of $60-70 \%$ has been noted as compared to $100 \%$ severity of susceptible check in disease screening nurseries in Kenya. When present alone it does not provide sufficient level of resistance but in combination with other genes desirable level of resistance can be achieved. Much information is not available about the interaction of $\mathrm{Sr} 2$ and other genes in $\mathrm{Sr} 2$ complex. The adequate resistance level can be achieved by accumulating 4-5 minor genes. $\mathrm{Sr} 2$ was detected in several highly resistant old, tall Kenyan cultivars like Kenya plume and semi dwarf CIMMYT, cultivars Pavon F 76, Parula, Kingbird, Dollar bird etc. These cultivars show maximum disease severity of $10-15 \%$ with moderately resistant reactions. The gene $S r 2$ is tightly linked with Yr30 or has pleiotropic effects (Singh and HuertaEspino, 2000). A microsatellite (SSR) marker gwm533 is tightly linked and associated with the presence of this gene, which can be used to facilitate selection of this difficult to score gene (Spielmayer et al., 2003).

\section{$\operatorname{Lr} 34 / \mathrm{Yr} 18$}

Numerous genes conferring resistance to wheat rusts have been identified and used in wheat ( $T$. aestivum L.) breeding. However, several of these genes have been rendered ineffective due to emergence of new virulent races. Cultivars with the rust resistance gene Lr34 such as Frontana had effective durable rust resistance to leaf rust ( $P$. triticina). Although Lr34 has been used extensively in spring wheat grown in US, isolates of $P$. triticina with complete virulence to this gene had not been detected (Kolmer et al., 2003). It has been found that soft red winter wheats having Lr34 in combination with seedling resistant $L r 2 a, L r 9, L r 26$ were highly resistant while in combination with $\operatorname{Lr} 10, \operatorname{Lrl1}, \operatorname{Lrl} 8$ were moderately to low resistant in USA (Kolmer, 2009).

Lr34, which has recently been cloned and found to encode an ATP-binding cassette $(\mathrm{ABC})$ transporter of the $\mathrm{ABC}$ transporter 
subfamily $G$ (ABCG), formerly known as pleiotropic drug resistance (PDR) subfamily (Krattinger et al., 2009), is known to confer broad-spectrum resistance to at least four biotrophic diseases: leaf rust (Dyck et al., 1966), stripe rust (Singh, 1992b), stem rust (Dyck, 1987) and powdery mildew (Lillemo et al., 2008; Spielmeyer et al., 2005). Lr34 is also associated with a premature senescence of the leaf tips, commonly referred to as leaf tip necrosis (LTN) (Singh, 1992a).

\section{$\operatorname{Lr46/Yr29}$}

A slow rusting gene identified in the cultivar Pavon and was found located on chromosome $1 \mathrm{~B}$ by crossing with a monosomic series of adult plant leaf rust susceptible cultivar Lal Bahadur (Singh et al., 1998). This is the 2nd named minor gene involved in slow rusting. The leaf rust resistance gene Lr46 and yellow rust resistance gene $\mathrm{Yr} 29$ are tightly linked or Pleiotropic (William et al., 2003). Its effect is similar to $\mathrm{Lr} 34 / \mathrm{Yr} 18$ as it does not provide complete immunity to plants. Infected adult plants carrying Lr46 have longer latency period as compared to control without this gene (Martinez et al., 2001). The plants with this gene also show higher rate of fungal colonies abortion with out any chlorotic or necrotic effects and also decrease the colony size. The resistance conferred by this gene is not of hypersensitive type (Suenaga et al.,2003) determined that the microsatellite locus Xwmc44 is located 5.6-cM proximal to the putative QTL for Lr46. Leaf tip necrosis (Ltn) has been reported to be highly correlated with the presence of Lr46/Yr29 gene (Rosenwarne et al., 2010). Efforts are underway to clone this gene.

\section{Lr34/Yr18/Sr57/Pm38}

The $\mathrm{Lr} 34 / \mathrm{Yr} 18 / \mathrm{Sr} 57 / \mathrm{Pm} 38$ gene is a globally important genetic resource for wheat resistance breeding against leaf rust and stripe rust. It has also been shown to confer partial resistance to powdery mildew, and in some genetic backgrounds to stem rust. The locus has further been associated with tolerance to barley yellow dwarf virus. Lr34 has been widely used in wheat cultivars worldwide and its resistance has remained effective over many years (possibly more than 100), making it one of the few known resistance genes with a generally large effect and durability despite large-scale, agricultural use. The gene was first described as LrT2 (Dyck, 1977, 1987) and later identified in several distinct groups of genetic material, e.g. CIMMYT lines, Chinese landraces and Eastern European winter wheat material (Kolmer et al., 2008; Krattinger et al., 2009). The Lr34/Yrl8 gene acts quantitatively, i.e. it confers only partial resistance and generally has to be used in combination with other quantitatively acting resistance genes to provide sufficient resistance under heavy disease pressure. Lr34 is active specifically in the adult plant stage and the flag leaf is usually evaluated in assays of plants containing the gene against leaf and stripe rust as well as powdery mildew (McIntosh 1992; Singh 1992; Spielmeyer et al., 2005). Lr34/Yr18 activity is correlated with leaf tip necrosis (LTN) on the flag leaf which can be used as a phenotypic marker for Lr34/Yrl8 and which is also expressed in the absence of the pathogen (Dyck 1991; Lagudah et al., 2006). However, the expression of LTN is environmentally dependent and can vary greatly in different environmental conditions and genetic backgrounds. Lr34/Yrl8 was cloned by biparental mapping and positional cloning using integrated molecular marker information from several crosses as well as physical maps from the D genome of Aegilops tauschii and hexaploid wheat (Krattinger et al., 2009).

Based on the knowledge of the Lr34/Yrl8 gene sequence, gene-specific markers were developed and have proven to be highly 
diagnostic for the Lr34 gene (Lagudah et al., 2009; Dakouri et al., 2010). The analysis of eight independent mutants revealed that the same gene is in fact responsible for leaf and stripe rust resistances as well as LTN (Krattinger et al., 2009). Henceforth, we will refer only to Lr34, keeping in mind that it is a multi-pathogen resistance gene with a pleiotropic effect of leaf tip necrosis.

\section{Lr34/Yr18 compared to other cloned leaf rust or stripe rust resistance $(R)$ genes}

No major gene against stripe rust (Yr genes) has yet been isolated. The cloned $\operatorname{Yr} 36$ is a temperature-dependent resistance gene with no race specificity detected to date (Fu et al., 2009). Yr36 encodes a protein with an $\mathrm{N}$ terminal kinase domain a C-terminal lipid transfer (START) domain. Thus, the protein structure and possibly molecular mode of action is very different from $\operatorname{Lr} 34$.

Characterization and molecular mapping of Yr52 for high-temperature adult-plant resistance to stripe rust in spring wheat germplasm PI 183527

High-temperature adult-plant (HTAP) stripe rust resistance has proven to be race nonspecific and durable. However, genes conferring high-levels of HTAP resistance are limited in number and new genes are urgently needed for breeding programs to develop cultivars with durable high-level resistance to stripe rust. Spring wheat germplasm PI 183527 showed a high-level of HTAP resistance against stripe rust in germplasm evaluations over several years. To elucidate the genetic basis of resistance, we crossed PI 183527 and susceptible wheat line Avocet S. Adult plants of parents, F1, F2 and F2:3 progeny were tested with selected races under the controlled greenhouse conditions and in fields under natural infection. PI 183527 has a single dominant gene conferring HTAP resistance. Resistance gene analog polymorphism (RGAP) and simple sequence repeat (SSR) markers in combination with bulked segregant analysis (BSA) were used to identify markers linked to the resistance gene. A linkage map consisting of 4 RGAP and 7 SSR markers was constructed for the resistance gene using data from $175 \mathrm{~F} 2$ plants and their derived F2:3 lines. Amplification of nulli-tetrasomic, ditelosomic and deletion lines of Chinese Spring with three RGAP markers mapped the gene to the distal region (0.86-1.0) of chromosome 7BL. The molecular map spanned a genetic distance of $27.3 \mathrm{~cm}$, and the resistance gene was narrowed to a $2.3 \mathrm{~cm}$ interval flanked by markers Xbarc182 and Xwgp5258. The polymorphism rates of the flanking markers in 74 wheat lines were 74 and $30 \%$, respectively; and the two markers in combination could distinguish the alleles at the resistance locus in $82 \%$ of tested genotypes (Ren et al., 2012).

To determine the genetic relationship between this resistance gene and $\mathrm{Yr} 39$, a gene also on 7BL conferring HTAP resistance in Alpowa, a cross was made between PI 183527 and Alpowa. F2 segregation indicated that the genes were $36.5 \pm 6.75 \mathrm{~cm}$ apart. The gene in PI 183527 was therefore designed as $\operatorname{Yr} 52$. This new gene and flanking markers should be useful in developing wheat cultivars with high level and possible durable resistance to stripe rust (Ren et al., 2012).

\section{Characterization of a major QTL for adult plant resistance to stripe rust in US soft red winter wheat}

Pioneer 26R61 has provided effective resistance to stripe rust for 10 years. To elucidate the genetic basis of the resistance, a mapping population of 178 recombinant inbred lines (RILs) was developed using single-seed descent from a cross between Pioneer 26R61 and the susceptible cultivar 
AGS 2000. A genetic map with 895 markers covering all 21 chromosomes was used for QTL analysis. One major QTL was detected, explaining up to $56.0 \%$ of the mean phenotypic variation, flanked by markers Xbarc124 and Xgwm359, and assigned to the distal $22 \%$ of the short arm of wheat chromosome 2A. Evidence showed that it was different from $\mathrm{Yrl7}$ derived from Ae. ventricosa, the only formally named $\mathrm{Yr}$ gene in 2AS, and the QTL was temporarily designated as YrR61. In addition, a minor QTL, QYr.uga-6AS, probably conditioned high temperature adult plant resistance. The QTL explained 6-7\% of the trait variation. Preliminary test of the flanking markers for YrR61, in two cultivars and two promising breeding lines with Pioneer 26R61 in their pedigree, indicated that $\operatorname{YrR61}$ was present in these cultivars and lines, and these markers could therefore be used in marker assisted selection (Hao et al., 2011).

\section{Characterization of $\mathrm{Yr54}$ and other genes} associated with adult plant resistance to yellow rust and leaf rust in common wheat Quaiu 3

Quaiu 3, a common wheat line developed at the International Maize and Wheat Improvement Center (CIMMYT), is immune to $\mathrm{YR}$ in Mexico despite seedling susceptibility to predominant races. Quaiu 3 also shows immunity to LR in field trials and is known to possess the race-specific gene Lr42. A mapping population of 182 recombinant inbred lines (RILs) was developed by crossing Quaiu 3 with susceptible Avocet- YrA and phenotyped with LR and YR in field trials for 2 years in Mexico. Quantitative trait loci (QTL) associated with YR and LR resistance in the RILs were identified using Diversity Arrays Technology and simple sequence repeat markers. A large-effect QTL on the long arm of chromosome 2Dexplained $49-54 \%$ of the phenotypic variation in Quaiu 3 and was designated as Yr54. Two additional loci on $1 B L$ and 3BS explained 8-17 \% of the phenotypic variation for YR and coincided with previously characterized adult plant resistance (APR) genes Lr46/Yr29 and Sr2/Yr30, respectively. QTL on $1 \mathrm{DS}$ and $1 \mathrm{BL}$ corresponding to Lr42 and Lr46/Yr29, respectively, contributed $60-71 \%$ of the variation for LR resistance. A locus on 3D associated with APR to both diseases explained up to $7 \%$ of the phenotypic variance. Additional Avocet- Yr A-derived minor QTL were also detected for YR on chromosomes 1A, 3D, 4A, and 6A. $\operatorname{Yr} 54$ is a newly characterized APR gene which can be combined with other genes by using closely linked molecular markers (Basnet et al., 2013).

Genetic mapping of a putative Thinopyrum intermedium derived stripe rust resistance gene on wheat chromosome $1 B$

Rust resistance was transferred from Thinopyrum intermedium to common wheat, and the resulting introgression line (L693) exhibited all-stage resistance to the widely virulent and predominant Chinese pathotypes CYR32 and CYR33 and to the new virulent pathotype V26. There was no cytological evidence that L693 had alien chromosomal segments from Th. intermedium. Genetic analysis of stripe rust resistance was performed by crossing L693 with the susceptible line L661. F1, F2, and F2:3 populations from reciprocal crosses showed that resistance was controlled by a single dominant gene. A total $479 \mathrm{~F} 2: 3$ lines and 781 pairs of genomic simple sequence repeat (SSR) primers were employed to determine the chromosomal location of the resistance gene. The gene was linked to six publicly available and three recently developed wheat genomic SSR markers. The linked markers were localized to wheat chromosome 1B 
using Chinese Spring nulli -tetrasomic lines, and the resistance gene was localized to chromosome 1B based on SSR and wheat genomic information. A high-density genetic map was also produced. The pedigree, molecular marker data, and resistance response indicated that the stripe rust resistance gene in L693 is a novel gene, which was temporarily designated YrL693. The SSR markers that co-segregate with this gene (Xbarc187- 1B, Xbarc187-1B-1, Xgwm18-1B, and Xgwm11-1B) have potential application in marker-assisted breeding of wheat, and YrL693 will be useful for broadening the genetic basis of stripe rust resistance in wheat (Huang et al., 2014).

Novel QTL for stripe rust resistance on chromosomes $4 A$ and $6 B$ in soft white winter wheat cultivars

Stripe rust of wheat is a devastating disease in temperate regions when susceptible varieties are grown and environmental conditions sustain high disease pressures. With frequent and severe outbreaks, disease resistance is a key tool for controlling stripe rust on wheat. The identification of quantitative trait loci (QTL) involved in stripe rust resistance from the important US Pacific Northwest soft white winter wheat varieties "Eltan" and "Finch" was carried out. An F2:5 recombinant inbred line (RIL) mapping population of 151 individuals derived from the Finch -Eltan cross was developed through single seed descent. A linkage map comprising 683 unique single nucleotide polymorphism (SNP) loci and 70 SSR markers were used to develop 22 linkage groups consisting of 16 of the 21 chromosomes. Stripe rust data were collected on the RILs during the summers of 2012 to 2014. QTL analysis identified two genomic regions on chromosomes 4A (QYrel.wak-4A) and 6B (QYrfi.wak-6B) associated with resistance from Eltan and Finch, respectively. The results of the QTL analysis showed that QYrel.wak-4A and QYrfi.wak-6B reduced infection type and disease severity. Based upon both molecular and phenotypic differences, QYrel.wak-4A is a novel QTL for adult plant resistance (APR) to stripe rust (Klarquist et al., 2016).

\section{Genetic architecture of resistance to stripe rust in a global winter wheat germplasm collection}

Virulence shifts in populations of Puccinia striiformis f. sp. tritici (Pst), the causal pathogen of wheat stripe rust, are a major challenge to resistance breeding. The majority of known resistance genes are already ineffective against current races of Pst, necessitating the identification and introgression of new sources of resistance. Germplasm core collections that reflect the range of genetic and phenotypic diversity of crop species are ideal platforms for examining the genetic architecture of complex traits such as resistance to stripe rust. We report the results of genetic characterization and genome-wide association analysis (GWAS) for resistance to stripe rust in a core subset of 1,175 accessions in the National Small Grains Collection (NSGC) winter wheat germplasm collection based on genotyping with the wheat 9K single nucleotide polymorphism (SNP) iSelect assay and phenotyping of seedling and adult plants under natural disease epidemics in four environments. High correlations among the field data translated into high heritability values within and across locations. Population structure was evident when accessions were grouped by stripe rust reaction. GWAS identified 127 resistance loci that were effective across at least two environments, including 20 with significant genome-wide adjusted P-values. Based on relative map positions of previously reported genes and QTL, five of the QTL with significant genome-wide adjusted $\mathrm{P}$-values in this study represent potentially new loci. This 
study provides an overview of the diversity of Pst resistance in the NSGC winter wheat germplasm core collection, which can be exploited for diversification of stripe rust resistance in breeding programs (Peter et al., 2016).

\section{Markers assisted selection for multiple stripe rust resistance genes in spring bread wheat lines}

In order to stack combination of effective stripe rust resistance genes in future wheat genotypes, 99 spring wheat lines derived from the cross of Khyber-87 $\times$ Suleman-96 were screened with five closely linked PCR-based markers with stripe rust resistance genes $Y r 5$, Yr10, $Y r 17$ and $Y r 9$. Out of 99 experimental lines, S19M93 and S23M41 markers revealed the presence of $\mathrm{Yr} 5$ gene in 86 and 70 genotypes, respectively. While, Xpsp3000 suggested presence of $\mathrm{YrlO}$ gene in 66 genotypes, excluding two heterozygous lines PBS-07-60 and PBS-07-64. VENTRIUP-LN2 marker revealed that all genotypes were negative for $\operatorname{Yr} 17$ gene, while iag95 marker revealed presence of rye origin $\mathrm{Yr} 9$ gene in all genotypes. The presence of 1RS fragments were related to the poor bread making quality in certain wheat backgrounds. Furthermore, coexistence of both Xpsp3000 and iag95 markers are indicative of the potential interstitial recombination between wheat $1 \mathrm{BS}$ and rye $1 \mathrm{RS}$ chromatin or the presence of $1 R S$ fragments on more desirable wheat chromosomes 1A or 1D (Ullah et al., 2016).

\section{References}

Basnet B. R., Singh R. P. Ibrahim A. M. H., Herrera-Foessel S. A., Huerta-Espino J. Lan C., Rudd J. C., (2014), Characterization of Yr54 and other genes associated with adult plant resistance to yellow rust and leaf rust in common wheat Quaiu 3. Mol Breeding. 33:385-399.

Basnet BR (2012) Molecular characterization of durable yellow and leaf rust resistance in two wheat populations. PhD dissertation, Texas A\&M University, College Station, TX.

Basnet BR, Singh RP, Herrera-Foessel SA, Ibrahim AMH, Huerta-Espino J, CalvoSalazar V, Rudd JC (2013) Genetic analysis of adult plant resistance to yellow rust and leaf rust in common spring wheat 'Quaiu 3'. Plant Dis 97:728-736.

Bayles RA, Flath K, Hovmøller MS, de Vallavieille-Pope C (2000) Breakdown of the Yr17 resistance to yellow rust of wheat in northern Europe. Agronomie 20:805-811.

Bolton MD, Kolmer JA, Garvin DF (2008) Wheat leaf rust caused by Puccinia triticina. Mol Plant Pathol 9:563-575.

Bulli P., Zhang J., Chao S., Chen X., Pumphrey M. (2016) Genetic Architecture of Resistance to Stripe Rust in a Global Winter Wheat Germplasm Collection. G3: Genes|Genomes|Genetics. doi:10.1534/g3.116.028407.

Chen XM (2005) Epidemiology and control of stripe rust [Puccinia striiformis f. sp. tritici] on wheat. Can J Plant Pathol 27:314-33

Chen XM (2007) Challenges and solutions for stripe rust control in the United States. Aust J Agric Res 58:648-655.

Chen, X.M. Review Article: Hightemperature adult-plant resistance, key for sustainable control of stripe rust. Am. J. Plant Sci. 2013, 4, 608-627. [CrossRef]

Collard, B.C.Y.; Mackill, D.J. Markerassisted selection: An approach for precision plant breeding in the twentyfirst century. Philos. Trans. R. Soc. B 2008, 303, 557-572. 
Dakouri A, McCallum BD, Walichnowski AZ, Cloutier S (2010) Fine-mapping of the leaf rust Lr34 locus in Triticum aestivum (L.) and characterization of large germplasm collections support the $\mathrm{ABC}$ transporter as essential for gene function. Theor Appl Genet 121:373384.

Distelfeld, A.; Uauy, C.; Fahima, T.; Dubcovsky, J. Physical map of the wheat high-grain protein content gene $G p c-B 1$ and development of a highthroughput molecular marker. New Phytol. 2006, 169, 753-763.

Dyck PL (1977) Genetics of leaf rust reaction in three introductions of common wheat. Can J Genet Cytol 19:711-716.

Dyck PL (1987) The association of a gene for leaf rust resistance with the chromosome 7D suppressor of stem rust resistance in common wheat. Genome 29: 467-469.

Dyck PL (1991) Genetics of adult-plant leaf rust resistance in Chinese Spring and Sturdy wheats. Crop Sci 31:309-311.

Dyck PL, Samborski DJ, Anderson AG (1966) Inheritance of adult plant resistance derived from the common wheat varieties Exchange and Frontana. Can J Genet Cytol 8: 665-671.

$\mathrm{Fu}$ D, Uauy C, Distelfeld A, Blechl A, Epstein, L, Chen X, Sela, H, Fahima T, Dubcovsky J (2009) A kinase-START gene confers temperature-dependent resistance to wheat stripe rust. Science 323:1357-1360.

Fu DL, Uauy C, Distelfeld A, Blechl A, Epstein L, Chen XM, Sela H, Fahima T, Dubcovsky J (2009) A kinase-START gene confers temperature-dependent resistance to wheat stripe rust. Science 323:1357-1360.

Hao Y., Chen Z., Wang Y., Bland D., Buck J., Brown-Guedira G., Johnson., (2011) Characterization of a major QTL for adult plant resistance to stripe rust in
US soft red winter wheat. Theor Appl Genet. 123:1401-1411.

Herrera-Foessel S, Lagudah E, Huerta-Espino J, Hayden M, Bariana H, Singh D, Singh R (2011). New slow-rusting leaf rust and stripe rust resistance genes Lr67 and Yr46 in wheat are pleiotropic or closely linked. Theor Appl Genet 122:239-249.

Herrera-Foessel S, Singh R, Huerta-Espino J, Rosewarne G, Periyannan S, Viccars L, Calvo-Salazar V, Lan C, Lagudah E (2012) Lr68: a new gene conferring slow rusting resistance to leaf rust in wheat. Theor Appl Genet 124:14751486.

Hiebert CW, Thomas JB, McCallum BD, Humphreys DG, Depauw RM, Hayden MJ, Mago R, Schnippenkoetter W, Spielmeyer W (2011) An introgression on wheat chromosome 4DL in RL6077 (Thatcher 6/PI 250413) confers adult plant resistance to stripe rust and leaf rust (Lr67). Theor Appl Genet 121:1083-1091.

Huang Q., Li X., Chen W. Q., Xiang Z. P., Zhong S. F., Chang Z. J., Zhang M., Zhang H. Y., Tan F. Q., Ren Z. L., Luo P. G., (2014). Genetic mapping of a putative Thinopyrum intermediumderived stripe rust resistance gene on wheat chromosome 1B. Theor Appl Genet. 127:843-853.

ICARDA (2011) Research to actionstrategies to reduce the emerging wheat stripe rust disease. International wheat stripe rust symposium, Aleppo, Syria.

Klarquist E. F., Chen X. M. and Carter A. H., (2016) Novel QTL for Stripe Rust Resistance on Chromosomes 4A and 6B in Soft White Winter Wheat Cultivars. Agronomy 2016, 6, 4 . doi:10.3390/agronomy6010004

Kolmer JA (2009) Postulaton of leaf rust resistant genes in selected soft red winter wheats. Crop Sci 43: 1266-1274. 
Kolmer JA, Singh RP, Gravin DF, Vicaars L. William HM, Huerta-Espino J, Ogbonnayya FC, Raman H, Orford S, Bariana HS and Lagudha ES (2008) Analysis of Lr34/Yr18 rust resistance region in wheat germplasm. Crop Sci. 48: 1841-1852.

Krattinger SG, Lagudah ES, Spilmeyer W, Singh RP, Huerta-Espinno J, McFadden H, Bossolini E, Selter LL, Keller B (2009) A putative ABC transporter confers durable resistance to multiple fungal pathogen in wheat. Science 323: 1360-1363

Lagudah ES, McFadden H, Singh RP, HuertaEspino J, Bariana HS, Spielmeyer W (2006) Molecular genetic characterization of the $\mathrm{Lr} 34 / \mathrm{Yr} 18$ slow rusting resistance gene region in wheat. Theor Appl Genet 114:21-30.

Lillemo M, Asalf B, Singh R, Huerta-Espino J, Chen X, He Z, Bjørnstad A (2008) The adult plant rust resistance loci Lr34/Yrl8 and Lr46/Yr29 are important determinants of partial resistance to powdery mildew in bread wheat line Saar. Theor Appl Genet 116:11551166.

McIntosh RA (1992) Close genetic linkage of genes conferring adult-plant resistance to leaf rust and stripe rust in wheat. Plant Pathol 41:523-527.

McIntosh RA, Dubcovsky J, Rogers WJ, Morris C, Appels R, Xia XC (2012) Catalogue of gene symbols for wheat: 2012 supplement. http://www.shigen.nig.ac.jp/wheat/kom ugi/genes/macgene/supplement2012.pdf

McIntosh, R.A.; Wellings, R.A.; Park, R.F. Wheat Rusts: An Atlas of Resistance Genes; CSIRO Publications: East Melbourne, VIC, Australia, 1995; pp. 20-26.

McIntosh, R.A.; Yamazaki, Y.; Dubcovsky, J.; Rogers, J.; Morris, C.; Appels, R.; Xia, X.C. Catalogue of Gene Symbols for Wheat. In Proceedings of the 12th International Wheat Genetics Symposium, Yokohama, Japan, 8 September 2013; Springer: Tokyo, Japan, 2015.

Murphy, L.R.; Santra, D.; Kidwell, K.; Yan, G.Y.; Chen, X.M.; Campbell, K.G. Linkage maps of wheat stripe rust resistance genes $\mathrm{Yr} 5$ and $\mathrm{Yr} 15$ for use in marker-assisted selection. Crop Sci. 2009, 49, 1786-1790.

Naz AA, Kunert A, Lind A, Pillen P, Le'on J (2008) AB-QTL analysis in winter wheat: II. Genetic analysis of seedling and field resistance against leaf rust in a wheat advanced backcross population. Theor Appl Genet 116:1095-1104.

Ren R. S., Wang M. N., Chen X. M., Zhang Z. J., (2012). Characterization and molecular mapping of Yr52 for hightemperature adult-plant resistance to stripe rust in spring wheat germplasm PI 183527. Theor Appl Genet. 125:847857.

Roelfs, A.P.; Singh, R.P.; Saar, E.E. Rust Diseases of Wheat: Concepts and Methods of Disease Management; CIMMYT: Mexico, D.F., Mexico, 1992; pp. 1-81.

Rosenwarne G, Singh RP, William W, Huerta-Espino J (2010) Identification of phenotypic and molecular markers associated with slow rusting resistance gene Lr46. In Proc: 11th Inter. Cereal Rusts and Powdry Mildew Conference. Abstract 1.36.

Rosewarne G, Singh RP, Huerta-Espino J, Herrera-Foessel S, Forrest $\mathrm{K}$, Hayden M, Rebetzke G (2012) Analysis of leaf and stripe rust severities reveals pathotype changes and multiple minor QTLs associated with resistance in an Avocet 9 Pastor wheat population. Theor Appl Genet 124:1283-1294.

Singh A., Knox R. E., DePauw R. M., Singh A. K., Cuthbert R. D., Campbell H. L., 
Singh D., Bhavani S., Fetch T., Clarke F., (2013). Identification and mapping in spring wheat of genetic factors controlling stem rust resistance and the study of their epistatic interactions across multiple environments. Theor Appl Genet 126:1951 -1964.

Singh R, Huerta-Espino J, Bhavani S, Herrera-Foessel S, Singh D, Singh $P$, Velu G, Mason R, Jin Y, Njau P, Crossa J (2011) Race non-specific resistance to rust diseases in CIMMYT spring wheats. Euphytica 179:175-186.

Singh RP (1992a) Association between gene Lr34 for leaf rust resistance and leaf tip necrosis in wheat. Crop Sci 32:874878.

Singh RP (1992b) Genetic association of leaf rust resistance gene Lr34 with adult plant resistance to stripe rust in bread wheat. Phytopathology 82: 835-838.

Singh RP (2012) Pros and cons of utilizing major race-specific resistance genes versus partial resistance in breeding rust resistant wheat. In: The BGRI technical workshop, September 1-4, 2012, Beijing, China. http://www.globalrust. org/db/attachments/bgriworkshop/14/1/s ingh_web.pdf.

Singh RP and Rajaram S (1992) Genetics of adult plant resistance of leaf rust in 'Frontana' and three CIMMYT wheats. Genome 35: 24-31.

Singh RP, Huerta-Espino J (2000) Global monitoring of wheat rusts and assessment of genetic diversity and vulnerability of popular cultivars. Research. Highlight of CIMMYT wheat program: 1999-2000. CIMMYT, Mexico.

Singh RP, Mujeeb-Kazi A, Huerta-Espino J (1998) Lr46: a gene conferring slow rusting resistance to leaf rust in wheat. Phytopathology 88(9): 890-894.

Spielmeyer W, McIntosh RA, Kolmer J, Lugdah ES (2005) Powdry mildew resistance and $\operatorname{Lr34/Yr18}$ genes for durable resistance to leaf and stripe rust, co segregate at a locus on the short arm of chromosome 7D of wheat. Theor Appl Genet 111: 731-735.

Stubbs RW (1985) Stripe rust. In: Roelfs AP, Bushnell WR (eds) The cereal rusts, vol II. Academic Press, New York, pp 61101.

Suenaga K, Singh RP, Huerta-Espino J, William HM (2003) Microsattelite markers for gene $\mathrm{Lr} 34 / \mathrm{Yr} 18$ and other quantitative trait loci for leaf rust and stripe rust resistance in bread wheat. Phytopathology 93; 881-889.

Talha M., Swati, Harsha and Jaiswal J. P., (2016) Marker Assisted Detection Of Underutilized Potential Yr Genes In Elite Wheat Breeding Lines. SABRAO Journal of Breeding and Genetics 48 (3) 309-317, 2016

Ullah N., Ali N., Iqbal M., Din A. U., Shah A. H., Rahman I. U., Ahmad H., Inamullah., AliG. H., (2016) Markers assisted selection for multiple stripe rust resistance genes in spring bread wheat lines. International Journal of Biosciences | IJB | ISSN: 2220-6655 (Print), 2222-5234 (Online) http://www.innspub.net Vol. 8, No. 3, p. 63-74, 2016

Wan A, Zhao Z, Chen X, He Z, Jin S, Jia Q, Yao G, Yang J, Wang B, Li G, Bi Y, Yuan Z (2004) Wheat stripe rust epidemic and virulence of Puccinia striiformis f. sp. tritici in China in 2002. Plant Dis 88:896-904.

William HM, Singh RP, Huerta -Espino, J, Ortiz-Islas S, Hoisington D (2003). Molecular Marker mapping of leaf rust resistance gene Lr46 and its association with stripe rust gene $\mathrm{Yr} 29$ in wheat. Phytopathology.93:153-159.

$\mathrm{Xu}$ LS, Wang MN, Cheng P, Kang ZS, Hulbert SH, Chen XM (2013) Molecular mapping of Yr53, a new 
gene for stripe rust resistance in durum wheat accession PI 480148 and its transfer to common wheat. Theor Appl Genet 126:523-533.

Zhang H, Xia XC, He ZH, Li X, Li ZF, Liu DQ (2011) Molecular mapping of leaf rust resistance gene LrBil6 in Chinese wheat cultivar Bimai 16. Mol Breed 28:527-534.

Zhang, X., Zhong, S.B. and Yao, J.X. (1997). Cytological and powdery mildew resistance analyses of common wheat $\mathrm{x}$ Triticum araraticum hybrids and their progenies [Chinese]. Jiangsu Journal of Agricultural Sciences, 13: 185-187.
Zhao XL, Zheng TC, Xia XC, He ZH, Liu DQ, Yang WX, Yin GH, Li ZF (2008) Molecular mapping of leaf rust resistance gene $\mathrm{LrZH84}$ in Chinese wheat line Zhou 8425B. Theor Appl Genet 117:1069-1075.

Zhou H., Xia X., He Z., Li X., Wang C., Li Z., Liu D.,(2013) Molecular mapping of leaf rust resistance gene $\operatorname{LrNJ97}$ in Chinese wheat line Neijiang 977671.Theor Appl Genet. 126:21412147.

\section{How to cite this article:}

Sheikh F.A., Z.A. Dar, P.A. Sofi, Ajaz A. Lone and Nazir Ahmad Shiekh. 2017. Advanced Breeding Strategies to Mitigate the Threat of Yellow Stripe Rust of Wheat. Int.J.Curr.Microbiol.App.Sci. 6(6): 21-32. doi: https://doi.org/10.20546/ijcmas.2017.606.002 